\title{
PKM: DOKTER CILIK, AGEN PERUBAHAN KESEHATAN DAN LINGKUNGAN
}

\author{
Fransiska Ambarukmi P \\ fransiska.ambarukmi@lecture.unjani.ac.id \\ V. Santi Paramita \\ veronika.santi@lecture.unjani.ac.id

\section{UNIVERSITAS JENDERAL ACHMAD YANI}

\begin{abstract}
ABSTRAK
Program kemitraan dokter kecil ini bertujuan mengubah perilaku hidup bersih dan sehat dokter kecil dengan pendampingan dokter dan mahasiswa Fakultas Kedokteran Universitas Jenderal Achmad Yani (UNJANI). Dalam program ini, dokter kecil diberi kesempatan bermain peran sebagai dokter dan pasien dengan pendampingan dokter. Mereka mendapatkan gambaran lebih jelas tentang tugas dan tanggung jawab dokter dalam menangani pasien. Permasalahan yang dihadapi SD Santa Maria terkait program dokter kecil adalah: 1) Program kegiatan dokter kecil kurang menarik; 2) Kurangnya peminat program dokter kecil; 3) Dokter kecil belum memahami dengan baik tugas dan tanggung jawabnya 4) Terbatasnya sumber daya dan sumber dana; 5) Siswa belum memahami dan melaksanakan PHBS 6) Lingkungan sekolah belum sepenuhnya mendukung kesehatan siswa. Solusi yang telah dilaksanakan mengatasi permasalahan tersebut adalah: 1) pelatihan dan pendampingan kepada pembina program dokter kecil agar mampu menyusunan program kegiatan yang menarik; 2) Pelatihan dan pendampingan kepada dokter kecil agar memahami tugas dan tanggung jawabnya dengan baik; 3) Penyediaan sarana prasarana pendukung dokter kecil; 4) Menugaskan dokter kecil sebagai agen perubahan terkait PHBS; 5) Pelatihan kepada petugas kebersihan sekolah. Berbagai progam yang telah dilaksanakan dengan dukungan penuh guru dan siswa ini pada akhirnya mampu meningkatkan jumlah peserta ekstra kurikuler dokter kecil, meningkatkan pemahaman perilaku hidup bersih siswa, meningkatan kemampuan warga sekolah dalam memelihara kesehatan dan kebersihan lingkungan.
\end{abstract}

Kata kunci: Dokter Kecil, Agen Perubahan, PBHS.

\section{PENDAHULUAN}

Masalah kesehatan terkait erat dengan prestasi belajar siswa. Siswa yang sehat diharapkan mampu meraih prestasi belajar yang baik. Oleh karena itu, siswa perlu mendapatkan pengetahuan terkait perilaku hidup bersih dan sehat (PHBS), sehingga mampu menjaga kesehatan pribadi dan kebersihan lingkungannya.
Menyadari pentingnya membentuk perilaku hidup bersih dan sehat dalam rangka meningkatkan mutu pendidikan dan prestasi belajar siswa, pemerintah secara serius menanggapi permasalahan tersebut dengan mengeluarkan Peraturan Bersama 4 (empat) Menteri. Melalui Peraturan Bersama No. 6/2014, No. 73/2014, No. 41/2014 dan No. 81/2014, Menteri Pendidikan dan Kebudayaan, Menteri Kesehatan, Menteri Agama dan Menteri 
Dalam Negeri mengatur tentang Pembinaan dan Pengembangan Usaha Kesehatan Sekolah/Madrasah. Tujuan peraturan ini adalah untuk meningkatkan mutu pendidikan dan prestasi belajar peserta didik dengan meningkatkan perilaku hidup bersih dan sehat serta menciptakan lingkungan pendidikan yang sehat, sehingga memungkinkan pertumbuhan dan perkembangan yang harmonis peserta didik.

Anak usia sekolah merupakan kelompok umur yang sangat rawan terhadap masalah kesehatan. Walaupun tanggung jawab utama kesehatan anak usia sekolah berada di tangan orang tua/wali, tetapi sekolah dapat berperan dalam membentuk perilaku hidup bersih dan sehat peserta didiknyasejak dini. Hal ini mengingat siswa biasanya patuh pada peraturan dan perintah/anjuran gurunya. Oleh karena itu, siswa sekolah harus dibiasakan berperilaku hidup bersih dan sehat melalui kegiatan belajar di kelas dan diimplementasikan langsung di lingkungan sekolah dan rumah dalam kehidupan sehari-hari. Pembiasaan berperilaku hidup bersih dan sehat diharapkan mampu membentuk karakter dan perilaku peduli terhadap kesehatan pribadi dan kebersihan lingkungan, sehingga diharapkan mampu menularkan pada orang di sekitarnya yang pada akhirnya akan meningkatkan kualitas kesehatan masyarakat. Dengan demikian, siswa yang selalu berperilaku hidup bersih dan sehat, diharapkan mampu menjadi agen perubahan di lingkungan rumah dan sekitarnya. Vaske dan Kobrin (2001), Rosenberg, (2008), Bajd dan Lescanec (2011).

Taryatman (2016) menyimpulkan bahwa penerapan perilaku hidup bersih dan sehat (PHBS) di sekolah mampu menciptakan:

1. Sekolah yang bersih dan sehat sehingga peserta didik, guru, dan masyarakat lingkungan sekolah terlindungi dari berbagai gangguan dan ancaman penyakit

2. Meningkatnya semangat proses belajarmengajar yang berdampak pada prestasi belajar peserta didik
3. Meningkatnya citra sekolah sebagai institusi pendidikan, sehingga mampu menarik minat orang tua (masyarakat) untuk menyekolahkan anaknya di sekolah tersebut

4. Meningkatnya citra pemerintah daerah di bidang pendidikan, dan menjadi percontohan sekolah sehat bagi daerah lain.

Lebih lanjut Taryaman (2016) menyatakan bahwa pembentukan karakter perilaku hidup bersih dan sehat bagi siswa Sekolah Dasar dapat diterapkan dengan beberapa indikator berikut:

1. mencuci tangan dengan air mengalir dan memakai sabun

2. mengkonsumsi jajanan sehat dari kantin sekolah

3. menggunakan jamban yang bersih dan sehat

4. berolahraga teratur dan terukur

5. tidak merokok di sekolah

6. membuang sampah ke tempat sampah yang terpilah

7. memberantas jentik nyamuk

8. menimbang berat badan dan mengukur tinggi badan

9. memelihara rambut agar bersih dan rapih

10. memakai pakaian bersih dan rapih, dan 11. memelihara kuku agar selalu pendek dan bersih

Masing-masing indikator perilaku hidup sehat dan bersih mempunyai nilainilai karakter yang berbeda seperti nilai karakter disiplin, hidup sehat, cinta dan peduli lingkungan. Hasil penelitian Lina (2016) menunjukkan bahwa sebagian siswa SDN 42 Korong Gadang, Padang belum mampu menunjukkan perilaku hidup bersih dan sehat (PHBS). Siswa banyak yang terjangkit penyakit cacingan dan menderita karies gigi. Di samping itu, kesadaran siswa untuk menggunakan jamban bersih dan sehat masih rendah, dan siswa menolak untuk jajan sehat di kantin sekolah. Mengingat pentingnya merubah perilaku hidup bersih dan sehat sejak dini, maka salah satu implementasi dari kegiatan usaha kesehatan sekolah (UKS) adalah 
membentuk program dokter kecil sebagai kegiatan ekstra kurikuler siswa. Dokter kecil adalah peserta didik yang dipilih guru guna ikut melaksanakan sebagian usaha pelayanan kesehatan terhadap diri sendiri, keluarga, teman murid pada khususnya dan sekolah pada umumnya Hidayanti (2009), Martunus (2013), Nadia dkk (2012), Rahmawati (2015).

Program dokter kecil diharapkan mampu membentuk siswa sebagai agen perubahan dalam mewujudkan perilaku hidup bersih dan sehat. Oleh karena itu, pembinaan dan pengembangan dokter kecil di sekolah perlu dilakukan dengan baik dan terarah. Salah satu Sekolah Dasar di wilayah Cimahi yang telah menerapkan program dokter kecil adalah SD Santa Maria di Jl. Baros No. 8 Cimahi, sekitar 2 (dua) km dari lokasi kampus Universitas Jenderal Achmad Yani (UNJANI). Pimpinan sekolah memiliki komitmen yang tinggi dalam menerapkan perilaku hidup bersih dan sehat bagi para peserta didiknya serta peduli dalam menciptakan sekolah yang berwawasan lingkungan. Salah satu implementasinya, pihak sekolah menetapkan program dokter kecil sebagai salah kegiatan ekstra kurikuler bagi siswa kelas 4 hingga kelas 6. Namun demikian, pelaksanaan program dokter kecil di sekolah tersebut belum optimal karena terbatasnya kemampuan sumber daya dan sumber dana. Oleh karena itu, kegiatan Program Kemitraan Masyarakat (PKM) ini akan fokus pada upaya pembinaan dan pemberdayaan dokter kecil di kedua SD tersebut dalam upaya meningkatkan perilaku hidup bersih dan sehat siswanya.

\subsection{PERMASALAHAN MITRA}

Berdasarkan hasil wawancara dan pengamatan di lokasi, permasalahan dokter kecil yang terdapat di SD Santa Maria Cimahi adalah sebagai berikut:

1) Program dokter kecil belum dirancang dan dilaksanakan dengan baik dan menarik
2) Jumlah peserta ekstra kurikuler dokter kecil masih minim, kurang dari 5\% jumlah siswa

3) Dokter kecil belum sepenuhnya paham perilaku hidup bersih dan sehat

4) Dokter kecil belum memahami dengan baik tugas dan tanggung jawabnya sebagai dokter kecil.

5) Kegiatan pemeriksaan kesehatan sederhana belum dilaksanakan secara rutin, seperti pencatatan berat dan tinggi badan.

6) Sarana dan prasarana penunjang kegiatan dokter kecil masih terbatas, seperti kotak P3K belum memadai, minimnya obat-obatan yang tersedia, terbatasnya jumlah timbangan dan alat pengukur tinggi badan, termometer. Belum memiliki buku pedoman dan buku saku dokter cilik, media kampanye hidup bersih dan sehat.

7) Kebersihan dan kesehatan lingkungan sekolah perlu ditingkatkan, khususnya terkait kebersihan kamar mandi dan jamban serta pemantuan jentik nyamuk secara rutin.

Beberapa permasalahan yang dihadapi mitra tersebut menginspirasi Tim Pengabdian Masyarakat UNJANI untuk bermitra dengan pihak Pimpinan sekolah dalam pembinaan dan pemberdayaan dokter kecil dalam upaya mencapai tujuan usaha kesehatan sekolah (UKS). Dengan demikian, kegiatan pembinaan dan pemberdayaan dokter kecil diharapkan dapat meningkatkan mutu pendidikan dan prestasi belajar peserta didik dengan meningkatkan perilaku hidup bersih dan sehat serta menciptakan lingkungan pendidikan yang sehat, sehingga memungkinkan pertumbuhan dan perkembangan yang harmonis peserta didik.

\section{METODOLOGI PELAKSANAAN}

Perencanaan, pelaksanaan dan evaluasi Program Kemitraan Masyarakat Dokter kecil di SD Santa Maria dan SD Santo Yusup Cimahi selalu melibatkan kepala sekolah dan guru pembina dokter kecil. 
Masalah prioritas yang akan ditangani dalam program dokter kecil ini disusun bersama antara tim pengusul, guru pembina dokter kecil dan kepala sekolah. Pelaksanaan program dokter kecil akan dilaksanakan secara rutin setiap minggu sekali dengan melibatkan dosen dan mahasiswa FK dan FEB UNJANI. Dosen dan mahasiswa FK akan melakukan pelatihan terhadap guru pembina dokter kecil dan serta pelatihan terhadap dokter kecil. Dosen dan mahasiswa FEB akan membantu saat pendampingan pembuatan program kerja, pembuatan buku pedoman dan buku saku dokter kecil serta melakukan evaluasi program. Materi pembelajaran sosialisasi melalui pemutaran film akan disiapkan oleh dosen dan mahasiswa FEB.

Kampanye cinta lingkungan, hidup bersih dan sehat serta pencegahan penyakit menular akan dilaksanakan secara berkesinambungan dengan berbagai metode agar dapat membentuk/mengubah perilaku siswa. Metode yang dilakukan diantaranya melalui pemberitahuan pada saat upacara, disisipkan pada materi pembelajaran di kelas, pemasangan poster dan kewajiban mengimplementasikannya dalam kehidupan sehari-hari.

Pelatihan untuk meningkatkan kualitas kebersihan lingkungan sekolah, khususnya kebersihan kamar mandi dan jamban akan diberikan kepada para petugas kebersihan. Di samping itu akan dibuatkan standard operating procedure (SOP) secara tertulis agar mereka lebih memahami tugas dan tanggung jawabnya. Sedangkan pelatihan pemeriksaan jentik nyamuk kan diberikan kepada petugas kebersihan, tenaga administrasi dan beberapa guru yang ditugaskan. Kegiatan pelatihan dokter kecil akan dilaksanakan oleh dokter dan mahasiswa FK kedokteran UNJANI sedangkan pendampingan akan dilaksanakan secara rutin Budiharjo (2015). Dengan adanya program kegiatan tahunan, buku pedoman dan buku saku, sarana prasarana yang memadai serta materi kegiatan dan pelatihan yang sudah diberikan kepada pembina dokter kecil, diharapkan kegiatan dokter kecil pada tahun-tahun berikutnya dapat berlanjut secara berkesinambungan. Demikian pula terkait kegiatan pemeliharaan kesehatan lingkungan sekolah, dengan adanya SOP yang telah dibuat, diharapkan kegiatan akan dapat berjalan berkelanjutan.

\section{HASIL DAN LUARAN}

Sebagai evaluasi hasil pelaksanaan kegiatan, tim pengabdian masyarakat melakukan penilaian kepada para peserta pelatihan dengan menggunakan daftar tilik. Adapun gambaran hasil evaluasi kegiatankegiatan yang sudah dilaksanakan tersebut adalah sebagai berikut:

1. Keterampilan Dokter Cilik Dalam Melakukan Pemeriksaan Tanda Vital

Berdasarkan hasil penilaian menggunakan daftar tilik kepada 13 orang dokter cilik terdapat 9 orang di antaranya mampu mendapatkan skor di atas 80 yang masuk dalam katagori baik, 4 orang dengan skor di atas 60 masuk dalam katagori sedang dan tidak ada yang mendapat nilai di bawah 60. Hal tersebut seperti tampak pada Gambar 1.1.

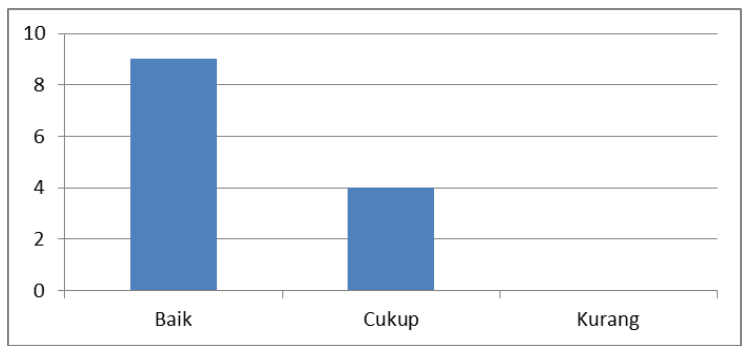

2. Keterampilan Dokter Cilik Dalam Melakukan Pengukuran Atromopetri

Berdasarkan hasil penilaian menggunakan daftar tilik kepada 13 orang dokter cilik terdapat 11 orang di antaranya mampu mendapatkan skor di atas 80 yang masuk dalam katagori baik, 2 orang dengan skor di atas 60 masuk dalam katagori sedang dan tidak ada yang mendapat nilai di bawah 60. Hal tersebut seperti tampak pada Gambar 1.2. 


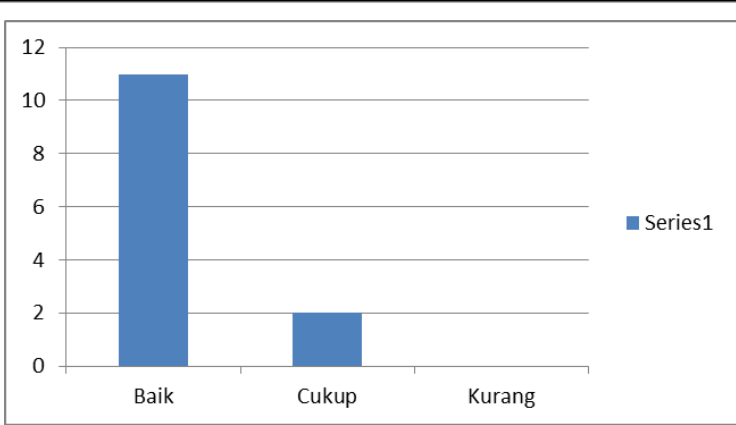

Gambar 1.2. Gambaran Evaluasi Kegiatan Pelatihan Pengukuran Antropometri Pada Dokter Cilik SD Santa Maria

3. Keterampilan Dokter Cilik Dalam Melaksanakan 7 Langkah Cuci Tangan

Berdasarkan hasil penilaian menggunakan daftar tilik kepada 13 orang dokter cilik terdapat 11 orang di antaranya mampu mendapatkan skor di atas 80 yang masuk dalam katagori baik, 2 orang dengan skor di atas 60 masuk dalam katagori sedang dan tidak ada yang mendapat nilai di bawah 60. Hal tersebut seperti tampak pada Gambar 1.3.

4. Keterampilan Dokter Cilik dalam Melakukan Sikat Gigi yang Benar

Berdasarkan hasil penilaian menggunakan daftar tilik kepada 32 orang dokter cilik terdapat 22 orang di antaranya mampu mendapatkan skor di atas 80 yang masuk dalam katagori baik, 10 orang dengan skor di atas 60 masuk dalam katagori sedang dan tidak ada yang mendapat nilai di bawah 60 . Hal tersebut seperti tampak pada Gambar 1.4.

5. Keterampilan Petugas Sekolah dalam Pemantauan Jentik Nyamuk

Berdasarkan hasil penilaian menggunakan daftar tilik kepada 6 orang petugas sekolah terdapat 5 orang di antaranya mampu mendapatkan skor di atas 80 yang masuk dalam katagori baik, 1 orang dengan skor di atas 60 masuk dalam katagori sedang dan tidak ada yang mendapat nilai di bawah 60 . Hal tersebut seperti tampak pada Gambar 1.5.

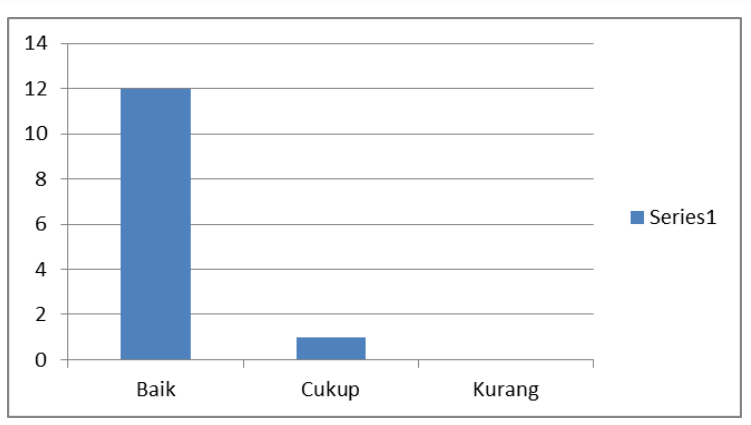

Gambar 1.3. Gambaran Evaluasi Kegiatan Pelatihan 7 Langkah Cuci Tangan Pada Dokter Cilik SD Santa Maria

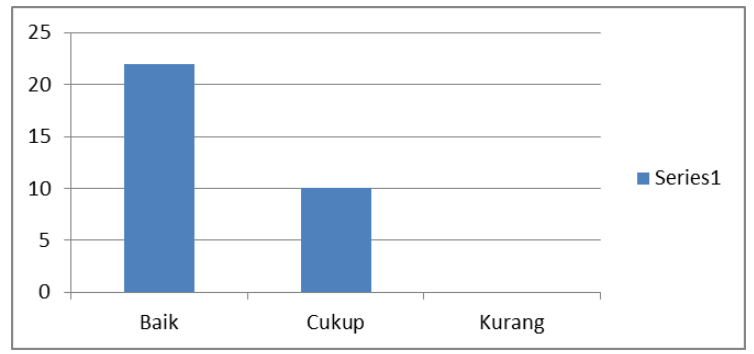

Gambar 1.4. Gambaran Evaluasi Kegiatan Pelatihan Sikat Gigi Yang Benar Pada Dokter Cilik SD Santa Maria

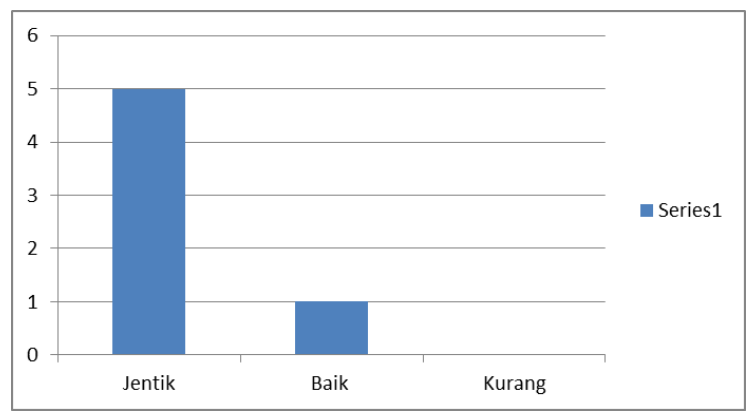

Gambar 1.5. Gambaran Evaluasi Kegiatan Pelatihan Pemantauan Jentik Nyamuk Pada Petugas SD Santa Maria

6. Tingkat Kehadiran Peserta Pembinaan Dokter Kecil dan Petugas Sekolah

Jumlah peserta pembinaan dokter kecil di SD Santa Maria Cimahi sebelum Tahun Ajaran 2019 adalah sebanyak 20 siswa dan bertambah pada Tahun Ajaran 2019 menjadi 32 orang. Dalam kurun waktu dari 10 April 2019 hingga 13 Agustus 2019 terdapat 6 kali pembinaan. 
Tabel 1. 1 Presentase Kehadiran Kegiatan Pelatihan Dokter Cilik dan Petugas Kesehatan SD Santa Maria

\begin{tabular}{|c|c|c|c|c|c|}
\hline $\begin{array}{l}\mathbf{N} \\
\mathbf{0}\end{array}$ & $\begin{array}{c}\text { Tangg } \\
\text { al }\end{array}$ & Materi & $\begin{array}{c}\text { Hadi } \\
\mathbf{r}\end{array}$ & $\begin{array}{c}\text { Tida } \\
\mathbf{k} \\
\text { Hadi } \\
\mathbf{r}\end{array}$ & $\begin{array}{c}\text { Persenta } \\
\text { se } \\
\text { Kehadira } \\
\text { n }\end{array}$ \\
\hline 1 & $\begin{array}{l}\text { Rabu, } \\
10 \\
\text { April } \\
2019\end{array}$ & $\begin{array}{l}\text { Pelatihan } \\
\text { keterampil } \\
\text { an dokter } \\
\text { kecil } \\
\text { dalam } \\
\text { melakukan } \\
\text { pemeriksa } \\
\text { an tanda } \\
\text { vital } \\
\text { seperti } \\
\text { menghitun } \\
\text { g nadi, laju } \\
\text { pernapasan } \\
\text { dan } \\
\text { mengukur } \\
\text { suhu } \\
\text { badan. }\end{array}$ & 13 & 7 & $65 \%$ \\
\hline 2 & $\begin{array}{l}\text { Rabu, } \\
10 \\
\text { April } \\
2019\end{array}$ & $\begin{array}{l}\text { Pengukuran } \\
\text { Antropomet } \\
\text { ri }\end{array}$ & 13 & 7 & $65 \%$ \\
\hline 3 & $\begin{array}{l}\text { Rabu, } \\
17 \\
\text { April } \\
2019\end{array}$ & $\begin{array}{l}\text { Penyakit } \\
\text { Menular } \\
\text { dan } \\
\text { pelatihan } 7 \\
\text { langkah } \\
\text { cuci tangan }\end{array}$ & 13 & 7 & $65 \%$ \\
\hline 4 & $\begin{array}{l}\text { Selasa, } \\
6 \\
\text { Agustu } \\
\text { s } 2019\end{array}$ & $\begin{array}{l}\text { Sosialisasi } \\
\text { dan } \\
\text { Simulasi } \\
\text { Mitigasi } \\
\text { Bencana }\end{array}$ & 32 & 0 & $100 \%$ \\
\hline 5 & $\begin{array}{l}\text { Selasa, } \\
13 \\
\text { Agustu } \\
\text { s } 2019\end{array}$ & $\begin{array}{l}\text { Prilaku } \\
\text { Hidup } \\
\text { dan sehat } \\
\text { Gigi }\end{array}$ & 32 & 0 & $100 \%$ \\
\hline 6 & $\begin{array}{l}\text { Selasa, } \\
13 \\
\text { Agustus } \\
2019\end{array}$ & $\begin{array}{l}\text { Pemantauan } \\
\text { Jentik } \\
\text { Nyamuk }\end{array}$ & 6 & 0 & $100 \%$ \\
\hline \multicolumn{5}{|c|}{ Presentase rata-rata kehadiran } & $82,5 \%$ \\
\hline
\end{tabular}

Dari Tabel 1.1. didapatkan data persentase kehadiran peserta pembinaan dokter kecil dari periode 23 April 2018 hingga 11 Mei 2018. Dari data tersebut dapat disimpulkan bahwa nilai persentase rata-rata kehadiran yaitu sebesar 94,1\% .

\section{KESIMPULAN DAN SARAN}

1. Kesimpulan

Pelaksanaan kegiatan pengabdian masyarakan berupa pelatihan dokter cilik dan petugas sekolah SD Santa Maria Cimahi telah terealisasi dengan rata-rata kehadiran peserta sebesar $82,5 \%$ dan menghasilkan skor evaluasi yang sebagian besar menunjukan katagori berketerampilan baik, sehingga diharapkan selanjutnya kemampuan para dokter kecil dan petugas sekolah dapat diimplementasikan untuk pendukung program kesehatan di sekolah.

\section{Saran}

Guna membentuk perilaku hidup bersih dan sehat, maka kegiatan monitoring dan evaluasi perlu terus dilakukan dalam periode-periode berikutnya sehingga dapat membentuk konsep PHBS sesuai harapan dari pelaksanaan kegiatan ini.

\section{UCAPAN TERIMAKASIH}

Atas terlaksananya kegiatan ini kami Tim Pengabdian masyarakat Universitas Jenderal Achmad Yani mengucapkan terima kasih kepada berbagai pihak yang telah mendukung dan juga terlibat aktif dalam kegiatan ini, antara lain:

1. Direktorat Jenderal Kemenetrian Riset dan Teknologi yang telah menyetujui hibah pendanaan atas kegiatan tersebut.

2. Koordinator Perguruan Tinggi Swasta Wilayah III Jawa Barat.

3. Rektor Universitas Jenderal Achmad Yani.

5. Ketua LPPM Universitas Jenderal Achmad Yani.

6. Dekan Fakultas Kedokteran dan Dekan Fakultas Ekonomi Universitas Jenderal Achmad Yani.

7. Para staf pengajar dosen dan non dosen, dokter muda dan dokter baru, alumni dari Fakultas Kedokteran dan Fakultas Ekonomi Universitas Jenderal Achmad Yani yang telah terlibat dan pelaksanaan kegiatan pengabdian masyarakat ini. 


\section{DAFTAR PUSTAKA}

Bajd, B. and Leščanec, T. (2011). The Influence of The Eco-School And Healthy School Projects on Environmentally Responsible Behavior of Primary School Pupils. Education and Health Care, 21, 79-85.

Budiharjo, Nova. (2015). Pelatihan Dokter Kecil Dalam Upaya Meningkatkan Perilaku Hidup Bersih Dan Sehat (Phbs) Siswa Di Sdn 2 Labuapi. Jurnal GaneÇ Swara Vol. 9 No.2 : 128-132. [10] Asniar. 2010. Pengembangan Sikap "Caring" Pada Anak Usia Sekolah Sebagai Upaya Promosi Kesehatan. Idea Nursing Journal Vol. I, No. $1: 32-46$.

Chapman, David and Kamala Sharma. (2001). Environmental Attitudes and Behavior of Primary and Secondary Students in Asian Cities: An Overview Strategy for Implementing an Ecoschools Programme. The Environmentalist. Volume 21, Issue 4, pp 265-272.

Cincera, Jan and Jan Krajhanzl. (2013). EcoSchools: What Factors Influence Pupils' Action Competence for ProEnvironmental Behaviour? Journal of Cleaner Production Vol 61, No. 25, pp 117-121.

Graaf, Ali Van Der . (2006). ECO-Schools: Trends and Divergences. A Comparative Study on ECO-School Development Processes in 13 Countries. Australian Journal of Environmental Education, Vol. 22, Issue 01, pp 123-125.

Hidayati, Listiyani., Suswardany, Dwi L., dan Ambarawati. (2009). Peningkatan Keterampilan Dokter Kecil Sebagai Upaya Memajukan Usaha Kesehatan Sekolah (UKS) Di Madrasah Ibtida'iyah Matholi'ul Falah Desa Buko Kecamatan Wedung Kabupaten Demak. Jurnal WARTA, Vol .12, No.1 : 8-14.

Krnel, D. and Naglic, S. (2009). Environmental Literacy Comparison
Between Eco-Schools and Ordinary Schools in Slovenia. Science Education International,Vol. 20, No.1, pp 5-24.

Lina, Henico Putri. (2016). Jurnal Promosi dan Pendidikan Kesehatan Indonesia. Vo. 4 No. 1, hal 92-103

Ozsoy, Sibel. Hamide Ertepinar. Necdet Saglam. 2012. Can Eco-Schools Improve Elementary School Students' Environmental Literacy Levels? AsiaPacific Forum on Science Learning and Teaching, Volume 13, Issue 2, Article 3.

Martunus. (2013). Peran Pelaksana Usaha Kesehatan Sekolah Dalam Kesehatan Anak SD Negeri No.026 Simpang Tiga Kecamatan Loa Janan Ilir. Jurnal Ilmu Sosiatri Vol. 1, No 2 : 51-64.

Michail, S. Stamou, A.G. and Stamou, G. P. (2007). Greek Primary School Teachers' Understanding of Current Environmental Issues: An Exploration of Their Environmental Knowledge and Images of Nature. Education, Vol. 91, No. 2, pp 244-259.

Nadia., Sabri, Rika., dan Nurdin, Yonrizal. (2012). Hubungan Pelaksanaan Program Usaha Kesehatan Sekolah Terhadap Perilaku Hidup Bersih Dan Sehat Pada Siswa SDN 13 Seberang Padang Utara. Jurnal Keperawatan Vol. 8, No.2 : 196-201.

J.Boeve-de Pauw, Van Petegem, Peter. (2013). The Effect of Eco-Schools on Children's Environmental Values and Behaviour. Journal of Biological Education, Vol. 47, No. 2, pp 96-103.

J. Boeve-de Pauw, and Van Petegem P. (2011). The Effect of Flemish EcoSchools on Student Environmental Knowledge, Attitudes, and Affect. International Journal of Science Education Vol. 33. No. 11, pp 15131538.

Pane, Kesha A. Suryono. 2012. Kajian Prinsip 'Eco Friendly Architecture', Studi Kasus: Sidwell Friends Middle School. Jurnal Arsitektur Daseng Unsrat Manado, Vol 1, No 1, pp 52-29. 
Palmberg, I. E. and Kuru, J. (2000). Outdoor Activities As A Basis For Environmental Responsibility. The Journal of Environmental Education, Vol. 31, No. 44, pp 32-36.

Rahmawati, Elya I., Soetopo, Hendyat., dan Maisyaroh. (2015). Manajemen Usaha Kesehatan Sekolah. Jurnal Manajemen Pendidikan Vol. 24, No. 6 : 571-577.

Rosenberg, E. (2008). Eco-Schools and the Quality of Education in South Africa: Realising the Potential. Southern African Journal of Environmental Education Vol 25, No 1.

Taryatman, (2016). Budaya Hidup Bersih dan Sehat. Jurnal Pendidikan ke SD-an Vol. 3 No.1, hal 8-13

Vaske, J.J., and Kobrin, K.C. (2001). Place Attachment And Environmentally Responsible Behavior. Journal of Environmental Education, Vol.32, No.4, pp 16-21.

Y1lmaz, Ö., Boone, W.J., Andersen, H.O. (2004). Views of Elementary and Middle School Turkish Students Toward Environmental Issues. International Journal of Science Education, 27(12), 1527-1546.

http://www.vedcmalang.com/p4tkmlg/index. php?view $=$ article $\&$ catid $=42 \% 3 \mathrm{Atrplh}$ \&id=313\%3Angelolaan- sekolahberwawasan- lingkungan\&option=com_content $\&$ Itemid $=54$

http://pendis.depag.go.id/lama/cfm/index.cf m?fuseaction $=\quad$ KajianBerita $\&$ Berita_ID $=10111 \&$ Su=7

http://blh.bantulkab.go.id/index.php?node= $96 \&$ menu $=5 \&$ sub $=1$

http://www.lpmpdki.web.id/ ArtikelPendidikan/ Menuju-SekolahBerwawasan-Lingkungan.html 